\title{
Improving Students' Argumentative Writing Skill through Rubric and Group Feedback
}

\author{
Karolis Anaktototy \\ English Education Study Program \\ Pattimura University, Ambon, Indonesia \\ E-mail: wakwyoya@gmail.com
}

\begin{abstract}
This study intends to gain comprehensive understanding about the implementation of rubric and group feedback and to know students' argumentative writing achievement. This study was conducted at the fourth semester students of English education study program of Teacher College Pattimura University in Ambon academic year 2015/2016. Action research method was used in this study. Data collection instruments used were students writing assessment rubrics, questionnaires, and record / field observation sheets of both observer and researcher. Descriptive statistics was used in analyzing data. The results shows that the synergy of rubric and group based feedback have improved students' argumentative writing skills. In pre cycle the average score of the students was 66.26 while in cycle I the average score was 72.09 . In cycle II the students' average score rose to 78.00 . Overall, more than $70 \%$ of the students have acquired good score for their argumentative writing. Rubric and group feedback strategy in fact has improved students' argumentative writing skill.
\end{abstract}

Key words: argumentative writing, rubric, group feedback

\section{INTRODUCTION}

Writing an essay in English has always been the most demanding task to be accomplished by Indonesian students. It is not only due to the context of learning English as a foreign language in which exposure to the use of English is mostly limited in the classroom but also because of the nature of writing which is the most difficult skill among the four language skills. Considering the complexity of writing skills there has been innovative ways proposed and tried out by language experts and practitioners to make the learning of writing easier and enjoyable for students. So far, the most common used approach to teach writing is the process approach. This approach is used because a step by step accomplishment of the writing task is needed in order to make the process of writing become reasonable and easier for students. It is also to show that writing is a multiple process not a single process.

Studying at university demands students to possess adequate writing skills in order for them to cope with given writing tasks. Moreover, as part of educated community they have to learn how to communicate knowledge and information they learned through writing.

In this research, an interview had been conducted at fourth semester academic year 2015/2016 of English education study program Pattimura University who enrolled in Writing 3 course. This course focuses to study argumentative essay. According to the students, argumentative essay is a difficult text to write because they have to argue logically based on facts and not merely on their own opinion. It certainly takes time to find references related to the topic that will be written and requires concentration to develop 
coherent and logical arguments. A learning process approach has been applied but it needs to be repacked using strategies or ways that empower students to learn so that the skill of writing can be mastered gradually. To overcome students argumentative writing problems as well as to improve their writing skills, rubrics and group based feedback were choosen to be applied in the teaching and learning process.

So far, rubric is used as a means of evaluating the results of students' writing. However, it can also be used as a learning tool or instructional tool. Covill (2012) stated that the use of rubrics as a learning style is in line with social cognitive theory to improve students' writing ability. Cognitive theory supports the use of rubrics to improve writing skills as rubric can facilitate cognitive processes at the time of writing. Plant (2015) suggested several reasons why a teacher or lecturer should use rubric in learning process, namely (a) Rubric can improve the work of the students and help them monitor their work; (b) Rubric is easy to be used and explained even for students who possess basic capabilities; (c) Rubric helps students to think and focus more on the quality of their work and the work of other students.

Besides, Andrade (2000) mentioned that through rubric, lecturer can deliver what he hopes to explain. The expectation of the lecturer on the task to be completed by the students can be clearly highlighted in a rubric. Moreover, rubric also provides information about what students are doing well and what should be improved. Rubric can also support the process of learning, skills development, development of comprehension, and critical thinking. Bennett Jr. (2008) mentioned that in the learning process, having clear and standardized criteria can save time in the evaluation process, help explain to students what to expect, shows what is taught, helping students to participate in their own learning process, helping classmates to give constructive feedback during the planning to the writing process, and help lecturers to provide a consistent and honest assessment.

Turgut and Kayaoglu (2015) also advocated rubric as a learning tool in writing instruction. They stated that the integration of rubric in the process of writing helps teachers to plan and shape writing instruction by breaking the course into measurable and observable components. In doing so students are expected to be able to develop their writing skill independently. According to Manuputty (2015) practice writing through a process approach provides many opportunities to apply rubric. The better students understand the learning rubric, the better they evaluate their own work without depending too much on the lecturer. Through learning rubric, the role of the lecturer will be changed as a facilitator of learning instead of as an agent of knowledge transfer. Furthermore, according to $\mathrm{Lu}$ and Zhang (2013), in order to write better arguments it is necessary to use rubric to evaluate the arguments of others. They cite the opinion of some experts about the inability of students to write and evaluate the argument and stated that the inability of students might be due to inadequate learning process, less prior knowledge of students, and inadequate teaching and training to write formally.

From these opinions of experts, it is clear that rubric has a strong theoretical foundation to be applied in teaching writing to improve student writing skills. Wyngaard and Gehrke in Turgut and Kayaoglu (2015) conducted a study on the relationship between the use of criteria measurement and improvement in writing skills using an analytical rubric. Students used analytic rubrics that contain clear descriptions for each component that will be developed. They discussed the rubric with students and equip students with the rubric to evaluate the results of their own writing. At the end of the semester they evaluate students' writing using the same rubric. They concluded that the use of rubrics is very effective to improve student writing. 
Meanwhile, according to Patchan, Schunn, and Clark (2011) without guidance, students usually edit their writing by focusing on revising grammar, misprinted word, or rewrite several sentences that are still not properly written while the addition of the substance and the development of writing is ignored. By doing so, the result of students' writing is not growing significantly. However, when students write using rubric, they will be able to change the way they revise their work. This certainly will affect the way and the quality of feedback given to their classmates. As a writing evaluation tool and guidelines for argumentative writing an analytic rubric has been prepared following the concept of rubric writing proposed by Mertler (2001) as seen in appendix A.

The analytic rubric was designed to evaluate students' ability to write argumentative essay which was broken down into three aspects namely content, organization, and language use. The score of each aspect was combined to gain the total score of every student. The same rubric was used by students to develop their writing.

Rubric can be integrated with group feedback to achieve a better writing result. After a student wrote an essay using rubric, the next activity is to provide feedback on the results of student writing that took place in their respective groups. Liu and Hansen in Abu Bakar, et.al (2012) stated that joint revision is supported by four theories, namely the theory of process writing, writing together (collaborative writing), as well as Vygotsky's perspectives interactionists and second language acquisition theory. Furthermore, Dix and Cawkwell (2011) assert that "the collaborative, social and cognitive dimensions of peer group response draw on pedagogical process approaches theories recognizing that when writing is responded to, it can be revisited, evaluated and ultimately revised to enhance the message." (p.45) Moreover, Pritchard and Honeycutt in Dix and Cawkwell (2011) mentioned that the effectiveness of the process of writing is associated with the dynamics of social and cognitive of feedback in group that is giving response to students' writing through criteria in order to have good writing results.

There are also some basic theories that put the emphasis on learning to write through group discussion. Grabe and Kaplan (1997) stated that one of the ways used to give feedback on the product of student writing is by interacting in group. This is based on understanding that the writing process carried out requires an audience other than the teacher in connection with the providing of feedback. In this process the students are more exposed to the language learned and used to respond to their group members' writing product. From this experience they can see the same problems and weaknesses in their own writing. At the same time they can use creative and innovative ideas that they get from the other group members' writing.. Students also need to learn to accept the logical response from the reader and use it constructively in the improvement of their writing.

Grabe and Kaplan (1997) also put forward several arguments in favor of the use of feedback in a group that is; (a). Research in the field of rhetoric, critical literacy, and social construction explain that knowledge is constructed through negotiations that occur in a community. Knowledge can not be released from a scientific community and knowledge will change when the community is reconstructing itself. This argument is used to support the idea of group-based feedback in learning writing skill. This perspective is also in line with the approach of readerresponse and post-structuralist to the analysis and interpretation of the text that is coherence of texts are created and recreated by the reader and is not inherent in the text. All three of these disciplines together provide a strong argument for an effective way for students to read texts and receive feedback; (b). The theoretical argument for feedback in group arises from a combination of disciplines of sociolinguistics and cognitive 
psychology (socio-cognitive). Socio-cognitive approach of learning argues that the best way to gain knowledge is through negotiation interactions. According to this view, students will develop the ability to write effectively when they engage in transactions involving their writing products and the products of their classmates; (c). Another argument that supports group feedback is derived from the results of research on cooperative learning. In the process of cooperative learning, the group can work together in various forms to complete tasks and projects that support the success of the learning process and is usually followed by writing activities at the end of the learning process.

Similarly, Tang and Tithecott (1999) stated that giving feedback in group is widely implemented in line with the changing paradigm of learning to write from productoriented to a process-oriented approach. This led to an emphasis on the process of helping students to know how to write through a process approach that is planning, writing the draft, and revising. So the feedback in a group provides an opportunity for students to practice their writing and evaluate others' writing based on defined criteria. In addition, the learning activities promote interaction among students to make students as a learning center. Through group feedback, lecturer creates a balance between learning undertaken by lecturer and student-centered activities.

In addition, $\mathrm{Hu}$, Zamel, and Rollinson in Kustati and Yuhardi (2014) explained that the reason for using the students' feedback in teaching writing skills is because; (a). Students find feedback from fellow students as a source of valuable information to supplement information provided by the lecturer; (b). Students found that feedback from lecturer is too general, vague, poorly understood, and more mandatory than the feedback from fellow students who are believed to be more specific; (c). Process of giving response and revision provide more effective revision and critical reading; and (d).
Feedback in group provides a real audience for students' writing.

The ideas proposed by researchers and practitioners are the evidence to assert that feedback is an important part of the process of learning to write. The use of feedback in group will gradually accustom students to take responsibility for their own work. In line with this, Hyland (2003) stated that feedback in group can be done since the beginning of writing activities. Students can work together in the pre-writing activities to discuss the idea in order to complete the writing assignment given. They can also give feedback to each other on the ideas that have been collected and the outline of writing that they have made. This is all intended to increase awareness and knowledge on how to develop students writing.

The use of feedback in a group is an attempt to make the learning process centered on the student. Through feedback in group there will be enthusiasm and motivation for students to learn and increase their participation in learning. Students will increase their level of cognitive awareness because they are aware of their strengths and weaknesses of their classmates and learn to solve problems they encounter. According to $\mathrm{Qu}$ and Yang (2010), the implementation of feedback and self-assessment will make the final evaluation to be more rational and better. It will make faculty understand the learning process of students.

Rubric has been the guidance for the students when composing their argumentative essay. However, when students start the process of giving feedback in their respective group, they were provided with a list of guiding questions to give them focus on giving feedback for their classmates writing product. Based on the description of learning problems related to argumentative writing faced by students as well as the study of theories that have been presented, this study was focused to answer the following questions: (1)How is the process of improving students argumentative writing skill through 
the integration of rubric and group-based feedback? (2) To what extend does the integration of rubric and group based feedback can increase students argumentative writing skill?

\section{METHODOLOGY}

This action research was conducted using the model of Kemmis and McTaggart consisting of four stages namely planning, action, observation, and reflection (Burns, 2010). This study was conducted to overcome students problem in writing argumentative essay. 42 students from English Study Program at Pattimura University who enrolled in this course were chosen as the population of the research. The instruments for this study were questionnaire, observation checklist, and students writing product.

The initial step was to observe the learning process of the students to identify their problems in writing argumentative easy. Based on the identified probems, rubric and group based strategy was chosen to be used integratedly to assist students in writing argumentative essay. The next step was planning the action using rubric and group based strategy to be implemented in the learning process. During the learning process the researcher and the collaborator took turns in observing and taking notes to see the effectiveness of the strategy and the dynamic interaction in group feedback. The last step was a reflection on the process of learning from the beginning until the end. The reflection was done to see whether data and notes taken were in accordance with the aim of the study or not. Besides, the reflection was intended to identify things that were not smoothly executed as expected during the learning process. The result of reflection was discussed with the collaborator for further improvement in the next cycle.

This study was implemented in two cycles. Quantitative data was gathered through students writing product at the end of each cycle. The writing product was scored based on an argumentative writing rubric. The rubric consist of three aspects of writing namely content, organization and language use. From these aspects, seven criteria were developed to score students writing ability.They were (a) Formulation of thesis statement; (b) Topic sentence supported by relevan information; (c) Thesis statement is supported by pro and cons argument; (d) Comprehensive introduction and conclusion paragraph; (e) Well organized information; (f) Appropriate vocabulary, and; (g) Acceptable grammar.

Quantitative data was obtained using Likert scale. While qualitative data was obtained through classroom observation and field record.

To answer the two questions of this study, descriptive statistics was used to analyze the quantitative data while for the qualitative data, content analysis was used to interpret the implementation of rubric and group based feedback during teaching and learning process.

\section{RESULTS AND DISCUSSIONS}

\section{Results}

The result showed that argumentative writing skill of students has increased from pre cycle to cycle I and from cycle I to cycle II. This is the impact of the application of rubrics and providing feedback in group. Students' average score in every cycle indicated that there has been a gradual improvement of student argumentative writing skill. For pre cycle, students' average score was 66.26 and the number of students who scored $\geq 70 \%$ was only $21.42 \%$. After the implementation of the first cycle, the average score of students increased to 72,09 or increased 5.83 points compared to the average score in pre cycle, while the number of students who achieved score $\geq 70 \%$ increased to $64.27 \%$ in cycle I. In the second cycle the average score rose to 78 , an increase of 5.91 points and the number of students who received grades $\geq 70$ rose to 95 , $23 \%$. Comparison of the average score of students can be seen in figure 1 . 


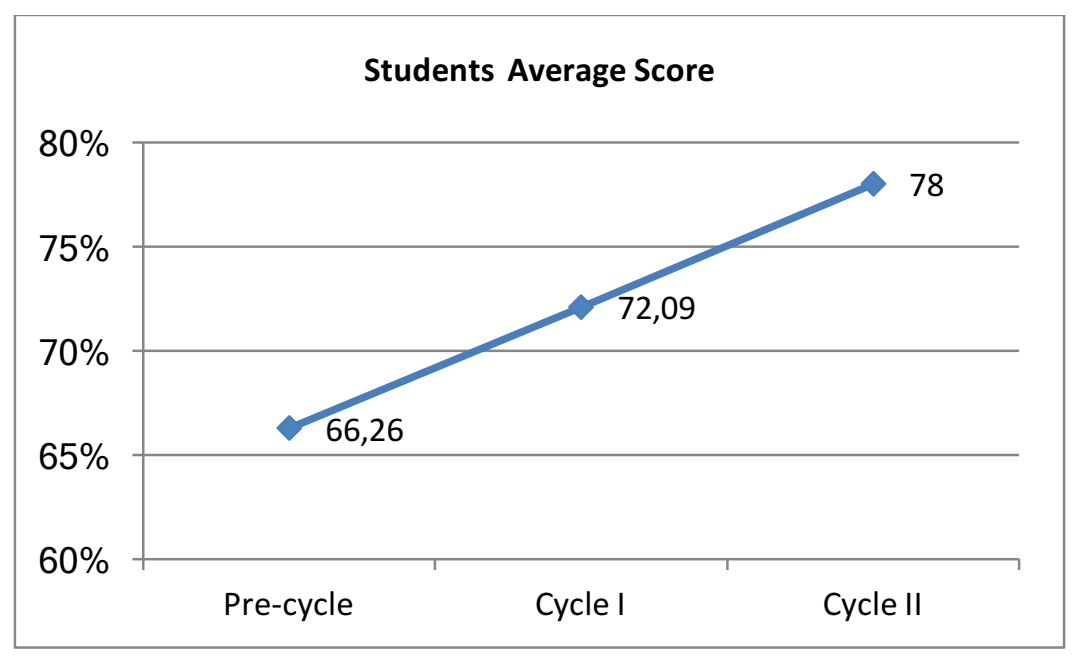

Figure 1: The Average Score of Students' Argumentative Writing for every Cycle

To have the average score of students' argumentative writing, three aspects of writing have been scored. The writing aspects were content, organization, and the use of language. The average score for each aspect can be seen in figure 2 .

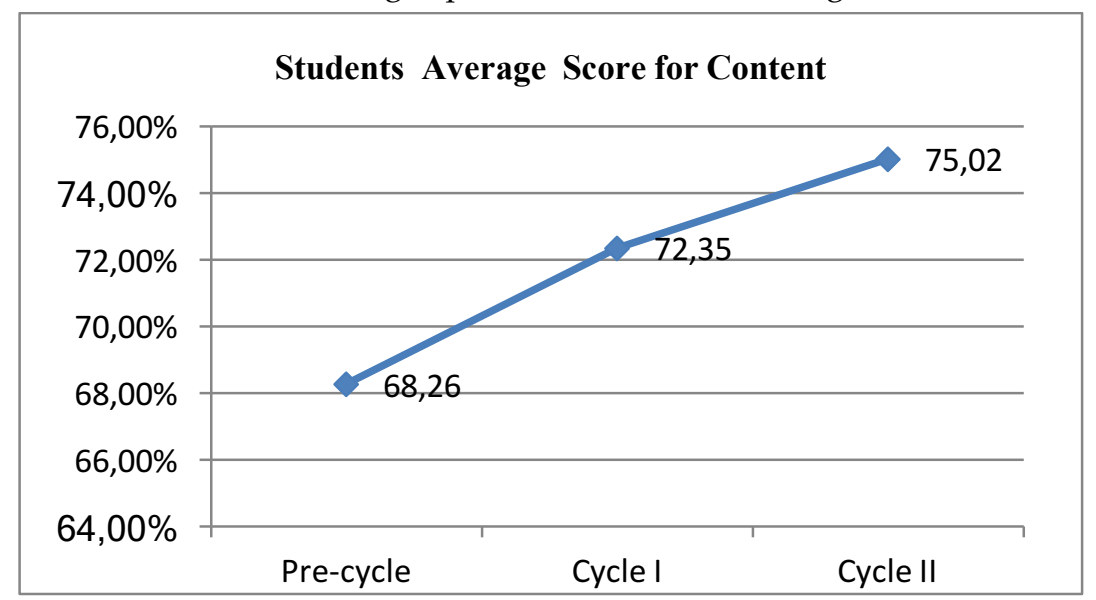

Figure 2. The Average Score of Students' Argumentative Writing for Content

As seen in figure 2 the average score of students for content in pre-cycle was 68.26 and in the first cycle students' score increased to 72.35 , a rise of 4.09 points. In the second cycle the average score was 75.02 , with an increase of 2.67 points. 


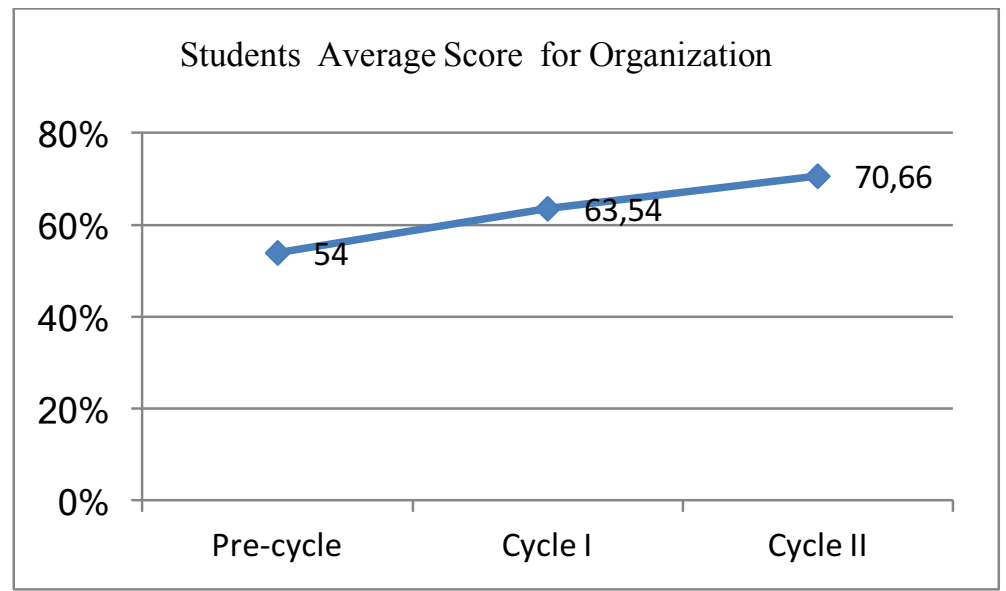

Figure 3. The Average Score of Students' Argumentative Writing for Organization

For writing organization as seen in figure 3 , the average score of pre-cycle was only 54 . After the action on the first cycle the average score rose to 63.54 , or increased 9.54 points. After the implementation of the second cycle then an increase in the average score became 70.66 or rose 7.12 points.

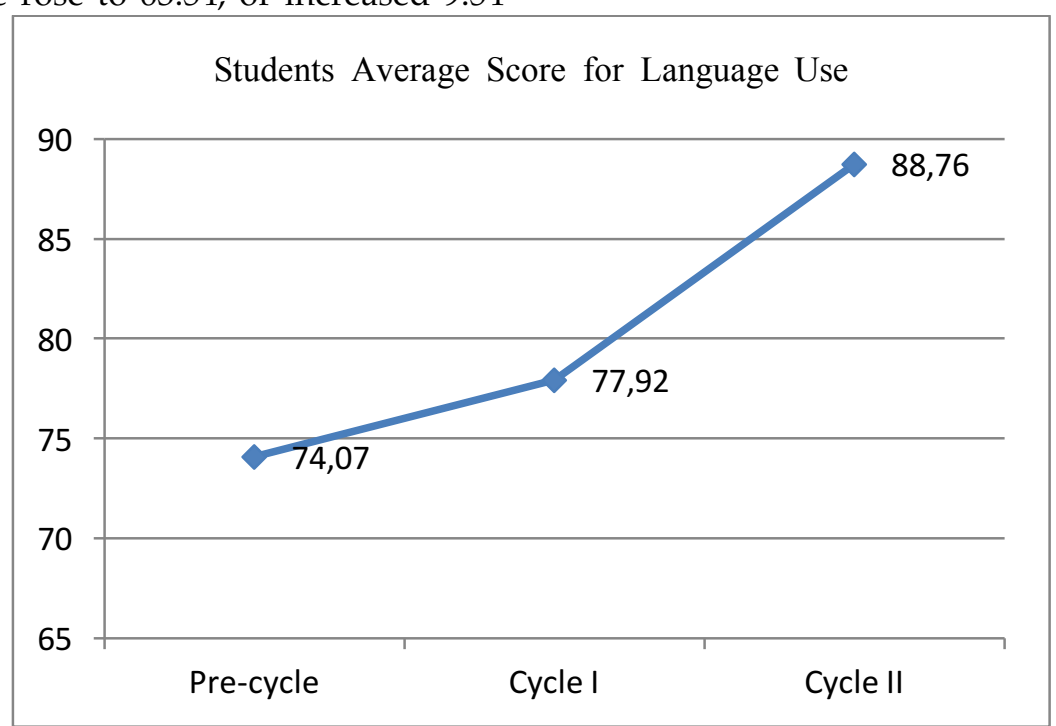

Figure 4. The Average Score of Students' Argumentative Writing for Language Use

The average score for language use in pre-cycle was 74.07 while for the first cycle the average score was 77.92. So there is an increase of 3.85 points. In the second cycle the average score rose to 88.26 , a rise of 10.34 points.

\section{Discussion}

Before students apply rubric for writing and give feedback in group it is necessary to explain in detail the indicators contained in the rubric as well as the guidelines of feedback. This is important because there is no doubt that providing feedback as an important part of the writing process often cannot be implemented properly by the students because there is no clear guidance on how to give feedback. As Cheng and Warren in Vasu, Ling, and Nimehchisalem (2016) stated that students require guidelines to provide feedback to their classmates because there is still a feeling of discomfort for them to provide feedback for the work of their classmates. Added by Glade, Hammersley, and Clark-Ellis that if the process of giving feedback would be successful then the student must have a clear understanding of what is feedback and why they should do it. 
If they understand the true reason for giving feedback then they will do it well.

Based on the result of data analysis, it can be explained that the learning process of writing argumentative essay through rubric and giving feedback in group has been done in a proper way. As a result it can improve student writing skills. The learning process was designed since the first meeting of the first cycle to the last meeting of the second cycle using rubric as well as feedback in group. Through this way of learning there has been a place for students to interact with each other to provide input to each other's writing. The impact of the feedback received is the emergence of awareness of students of any deficiencies shown by their peers thereby expanding their knowledge and writing skills.

In general students have made improvement in all three aspects. However, there are still some improvements needed for certain criteria in each aspect. For content aspect, improvement is needed for formulating thesis statement. Thesis statement is the key point to build the writer's argument which is of course followed by topic sentence and supporting details. The content of the writing is regarded sufficient if the thesis statement (claim) is supported with enough factual information. According to Bae and Lee cited by Aryadoust (2016) that the insufficiency of content in students' writing is due to limited knowledge of the topic or issue, lack of ideas to develop their writing, the weaknesses in analyzing and evaluating information and lack of argument technique.

For writing organization, students need to learn to write effective background that explicitly addresses the issue. Besides, students need to sharpen their ability in organizing facts and details in a coherent and cohesive way. It was found that students are still lack of ability in organizing information that they synthesized from different sources. Indeed, for writing organization the result of this researh is supported by Brammer and Rees (2007) who said that organization of writing is the most neglected aspect during writing and revising process by students.

The most neglected criterion for language use was the use of connectors to join different parts of the essay. The lack of connector usage also reflects the weaknesses of organizing ideas in their writing. It is a matter of fact that these three aspects have the same contribution to shape students over all ability in argumentative writing.

In the process of learning to write argumentative essay the integration of rubric and feedback in group is a new way because it has never been done before with the students at English education study program of teacher's college Pattimura University. Therefore, In terms of pedagogical aspect, the synergy between rubric and group based feedback is a new way that is done to address the problem of learning to write argumentative essay of students at English education study program of Pattimura University in Ambon. Empirically the implementation of rubric and feedback in group has proven to improve student argumentative writing in certain level. The result of this research may only be used in this group of students. However, the teaching procedures of using rubric and group feedback may be used as teaching reference for teacher and lecturer to improve students writing skill.

\section{CONCLUSION}

The evidence from this study implies that the learning process of argumentative essay through rubric and feedback in group has been performing well to increase students' writing skills. The result of the study has highlighted that during the learning process students were active and interactive with each other in their respective group to discuss and negotiate ways of improving their argumentative essay. The result of this study also has proven that students were motivated to use the rubric in writing and doing feedback in groups in order to revise their essay. The data analysis showed that the writing skills of the students increased 
gradually from one cycle to the next cycle. Therefore it can be concluded that rubric and group feedback strategy had been successfully empowered students to increase their argumentative essay writing skill.

Even though the integration of rubric and group based feedback strategy had successfully improved students' writing skills, it is suggested that prior to writing activity students should be trained to use rubric and how to give substantial corrective feedback. In this sense, a list of guided questions for giving feedback may be discussed with the students.

\section{REFERENCES}

Abu Bakar, et al. (2012). The Brief Review of Theoretical Underpinnings, Definitions and Typical Configurations of Collaborative Writing. International Journal of Applied Linguistics E English Literature, 1(4), 197-202

Andrade H., G. (2000). Using Rubrics to Promote Thinking and Learning. Educational Leadership. Vol. 57, (5), February, 1-7

Aryadoust V. " Examining the development of Paragraphs Writing ability for Tertiary ESL Students: A Continuous Assessment Study.Internet Download accessed at. http://www.ajsotl.edu.sg/article/examining-the-development-of-paragraph-writing-abilityof-tertiary-esl-students-a-continuous-

Bennett, P. E, Jr. (2008). Using Rubrics to Teach Science Writing. Essays on Teaching Excellence.Towards the Best in the Academy, 20(8), 1-6

Brammer C., \& Rees M. (2007). Peer review from the students' perspective: Invaluable or invalid. Composition Studies, 35(2), 71-85

Burns A. (2010). Doing Action Research in English Language Teaching: A Guide for Practitioners. New York: Routledge.

Covill, A. E. (2012). College Student's Use of a Writing Rubric: Effect on Quality of Writing, SelfEfficacy, and Writing Practices. The Journal of Writing Assessment, 5(1), 1-11.

Dix S., \& Cawkwell, G. (2011). The Influence of Peer Group Response: Building a Teacher and Student Expertise in the Writing Classroom. English Teaching: Parctice and Critique, 10(4), 4157

Glade F., Hammersley L., \& Clark-Ellis P. (2016). Considering the Value of Peer Response. Internet Download accessed at http://www.csuscsus.edu/wac/wac/teachers/peer response article.html,

Grabe W. dan Kaplan, Robert B. (1997). Theory and Practice of Writing. An Applied Linguistic Perpective. London and New York: Longman.

Hyland, K. (2000). Second Language Writing. New York: Cambridge University Press

Kustati M., \& Yuhardi, (2014). The Effect of the Peer-Review Technique on Students' Writing Ability.Studies in English Language and 'Education Journal, 1(2), 71-81.

Lu J. dan Zhang Z. (2013). Assessing and Supporting Argumentation with Online Rubrics. International Education Studies, 6(7), 66-77.

Manuputty R.(2015). Redifining conventional criteria and standard for teaching of argumentative essay. Jurnal Tahuri, 12(1), 69-74. 
Mertler, C. A., (2001). Designing scoring rubrics for your classroom. Practical Assessment, Research \& Evauation, 7(25), 1-9

Patchan, M.M., Schunn, C. D., \& Clark, R. J. (2011) Writing in natural science: Understanding the effects of different types of reviewers on the writing process. Journal of Writing Research, 2(3), 366-386.

Plant, A. (2015). Rubric use in the primary classroom: Ways to improve student writing. Internet Download accessed at https://readingrecovery.org/images/pdfs/Conferences/.../Plant_Amy.pdf

Qu W., \& Yang, S. (2010). A peer and self-assessment project implemented in practical group work. Journal of Language Teaching and Research, 1(6), 776-781

Tang, G. M., \& Tithecott, J. (1999). Peer response in ESL writing. TESL Canada Journal, 16(2), 2038.

Turgut, F., \& Kayaoglu, N.M. (2015). Using rubric as an instructional tool in EFL writing courses. Journal of Language and Linguistic Studies, 11(1), 47-58.

Vasu, K., Ling, C., H., \& Nimechchiselam V. (2016). Malaysian tertiary level ESL students' perceptions toward teacher feedback, peer feedback and self-assessment in their writing. International Journal of Applied Linguistics \& English Literature, 5(5), 158-167. 